\title{
Climate research for ecological monitoring and assessment: a New England example
}

\author{
Ellen J. Cooter*, Sharon K. LeDuc*, Lawrence Truppi* \\ Atmospheric Sciences Modeling Division, Air Resources Laboratory, National Oceanic and Atmospheric Administration, \\ Research Triangle Park, North Carolina 27711, USA
}

\begin{abstract}
The role of climate research as it applies to the emerging area of monitoring and assessment of ecological status, health and trends is discussed. Such applications require techniques that synthesize multiple, often interacting sources of climate-derived ecological stress. These stresses operate across multiple plant and animal species and span a range of temporal and spatial hierarchical scales. A working hypothesis of forest ecosystem/climate interactions is proposed. The basis of the hypothesis is the definition of climatological persistence and disturbance characteristics of a region. A climate database was assembled for the northeastern United States. Summaries that synthesize the spatial distribution, frequency, area and magnitude of climatological disturbance events are presented. These summaries are specifically designed to facilitate the testing of the interaction hypothesis proposed in the present study. Conclusions concerning climate stress in the area, as suggested by a 1961 to 1970 disturbance summary, are compared to results of recent research concerning declines in high elevation red spruce. The present research is the first step in the development of regional scale climate disturbance/forest ecosystem relationships. Future research will seek to link operational observations of forest status and behavior with these multivariate, climatological summaries.
\end{abstract}

\section{INTRODUCTION}

Recent environmental program reviews such as that contained in U.S. EPA (1990) place new emphasis on the evaluation of current ecological status and health and the estimation of anthropogenic risks to these systems. Ecosystems integrate the effects of natural as well as anthropogenic factors. Before accurate assess ments of ecological risk attributable to anthropogenic stresses such as acid rain or ozone can be made, ecosystem interactions with natural factors such as climate must be better understood.

Although climate research has an important role to play in such evaluations, movement of applied climatologists into the ecological monitoring and assessment arena presents new challenges. For instance, much of traditional agroclimatology has focussed on identifying 'primary drivers' or events for single, annual commercial

\footnotetext{
- On assignment to the Atmospheric Research and Exposure Assessment Laboratory, U.S. Environmental Protection Agency
}

crops such as corn, wheat or soybeans. Ecological assessment, on the other hand, requires the consideration of multiple, often interacting sources of stress operating across a large number of plant and animal species spanning many temporal and spatial hierarchical scales. Now we must begin to address the synthesis of all pertinent weather related factors. For instance, we must find ways of integrating the influence of multi-year drought, fire frequency, lightning strikes and insect population dynamics on Southern Pines ecosystems. Other difficult ecological settings include estuaries (Biggs et al. 1984) and wildlife habitat (Bailey 1986).

Although at first this may appear to be a daunting assignment, the ecological literature contains several unifying themes and permits the development of a working hypothesis suitable for ecological monitoring and assessment applications. Elements of such a hypothesis have been proposed by others, but its formalization and application to an operational program is a major advancement. The research summarized here demonstrates that regional climate summaries can be developed that provide estimates of pertinent eco- 
logical stress, applicable to single as well as multiple species situations. Research is continuing in the areas of regional expansion and special, more detailed studies of selected regional summaries.

\section{DEFINITIONS AND WORKING HYPOTHESIS}

A foundation of cross-disciplinary concepts and definitions is needed to address climate-ecosystem relationships. Many of these concepts and definitions are discussed in detail in Cooter et al. (1991), but those most pertinent to the present summary involve ecosystem persistence, recurrence and climate related disturbance or stress.

The concepts of ecological persistence and recurrence are closely related to principles of Markov processes. The Markov chain is a special case in which a finite (or countably infinite) number of outcomes or states are possible. A first-order Markov chain is one in which the probability of each state depends only the immediately preceding state. Botkin (1980) uses the concept of Markov chains to address some highly general ecological concepts. He suggests that ecosystem behavior through time can usually be described by 2 characteristics. First, particular ecosystem states come and go, or recur. Second, the recurrence of ecosystem states depends on the total amount of variation (the total number of possible states) which, in turn, must be bounded. This suggests the concepts of ecosystem persistence within bounds and the recurrence of specific ecosystem states.

Under this framework, long-term patterns of climatological means and variability can influence the establishment and persistence of dominant ecological landscapes, i.e. climate features set the bounds for the state space (Woodward 1987). Conversely, climate is dynamic, with weather conditions that can vary widely from one year to the next. Climate can, therefore, affect the range of variation (the number of possible states), the rate of recurrence of particular states and the average time that the ecosystem is in any of its possible states.

Climatologists study most frequently those environmental features that impact ecological persistence. Those aspects of climate that induce ecosystem recurrence or change (disturbance) can be more difficult to describe and thus are often less well understood. White \& Pickett (1985) propose the following definition: 'A disturbance is any relatively discrete event in time that disrupts ecosystem, community or population structure and changes resources, substrate availability or the physical environment.' This definition includes environmental fluctuations and destructive events, whether or not these are perceived as 'normal' for a
Table 1 Natural disturbance and associated ecosystems present in the northeastern United States (Pickett \& White 1985)

\begin{tabular}{|ll|}
\hline Disturbance & $\begin{array}{l}\text { Ecosystem or } \\
\text { geographical area }\end{array}$ \\
\hline Fire & $\begin{array}{l}\text { Boreal forest } \\
\text { Temperate forest } \\
\text { Coastal plain }\end{array}$ \\
Hurricane & Terrestrial \\
Other windstorms & Temperate forest \\
Ice storm & Temperate forest \\
Ice push on shores & Temperate and \\
Freeze damage & boreal forests \\
Fluctuating water levels & Various \\
in basins & Various \\
Droughts & Temperate forest \\
Alluvial processes & Various \\
Coastal processes & Various \\
Salinity changes & Various \\
Insect outbreaks & Various \\
Disease & Deciduous forest \\
\hline
\end{tabular}

particular system. Table 1 lists some natural disturbances and the ecosystems for which this definition of disturbance has been explored. Note that chronic as well as acute climatological disturbances have been included. Key descriptors of disturbance events include their spatial distribution, frequency, area and magnitude (White \& Pickett 1985).

Given this backdrop, the following hypothesis of climate-ecosystem relationships was constructed and used as a guide for subsequent climate research:

Climatological averages and ranges reflect one set of physical bounds on the number of possible ecosystem states represented within a landscape. Inter-annual climate variability acts as ecosystem disturbances. Disturbance events impact the persistence and recurrence of ecological states. Disturbance events vary with geographic location and can be described by their frequency, size and magnitude.

In order to test our ability to develop climate analyses pertinent to our working hypothesis, our research was directed towards climate/ecosystem interactions particular to a specific ecosystem type and geographic region. Simultaneously with the climate research described, an ecosystem monitoring program was initiated as a joint Environmental Protection Agency (EPA)/United States Department of Agriculture (USDA) endeavor. This program consisted of the EPA Environmental Monitoring and Assessment Program (EMAP) Forest Resource Group and the USDA New England Forest Health Monitoring (NEFHM) project (Norton \& 
Slonecker 1990, Miller 1991). Climate applications were directed towards addressing monitoring and assessment issues of interest to forest ecosystem monitoring and assessment in the 6 New England states of the northeastern U.S. The network of potential sampling areas (hexagons) is shown in Fig. 1.

\section{DATA DESCRIPTION}

Recent studies suggest general frameworks for describing climate features relevant to the analysis of forest landscapes and patch dynamics (Pickett \& White 1985, Forman \& Godron 1986). Climate data sets bearing on several major categories of ecosystem impacts, including those impacting growth, nutrient cycling rates and leaf and limb damage, were assembled. Pertinent climatological variables are described below.

\section{Drought}

Drought affects many aspects of forest health (Kozlowski 1985). Field observations of prolonged droughts in the Allegheny Plateau region of northwestern Pennsylvania revealed heavy mortality of shallow-rooted tree species such as hemlock Tsuga canadensis and yellow birch Betula alleghaniensis (Runkle 1985).
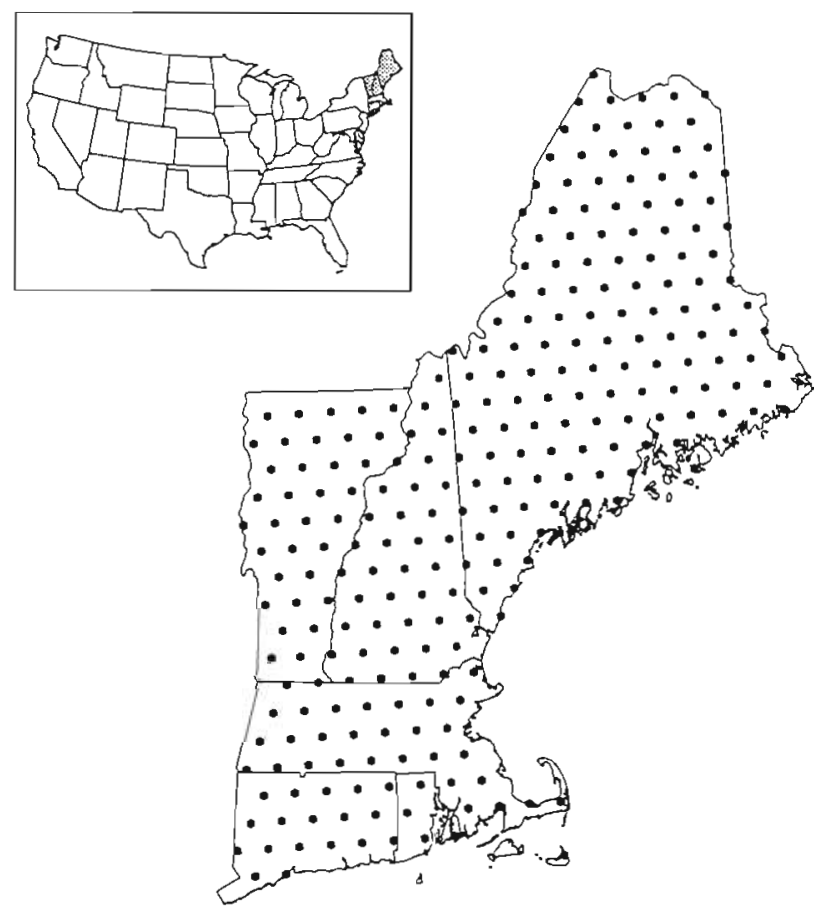

Fig. 1. The New England Forest Health Monitoring Program network of potential sampling areas
One indicator of meteorological drought is the Palmer Drought Severity Index (PDSI) (Palmer 1965). The PDSI represents the deviation of meteorological conditions from climatological 'normals' for a specified area or location. Although the temporal characteristics of the algorithm make it poorly suited for estimating the impact of short-term drought on biological systems (Sadowski 1975, Cooter 1982, Alley 1984), some scientists have found it to be a reasonable measure of longerduration drought stress for forest ecosystems (e.g. Puckett 1981, Zahner et al. 1989). The PDSI response time is on the same order as forest growth and development and its use to define large-scale climatological patterns is well established (Karl 1983, Eder et al. 1987).

\section{National Weather Service cooperative network data}

Much of the climatological data available for analysis are from the National Weather Service's cooperative network stations' 'summary of the day'. These daily arrays contain 24-hour maximum temperature, minimum temperature, total precipitation, snowfall and snow depth. An initial array of potential weather sites was provided based on a minimum 30-year period-ofrecord, current reporting status and completeness of record. Climatological variables to be studied were then designated and included: cumulative growing degree days, last spring freeze and warm spring snowfall dates.

\section{Growing degree days}

Solomon et al. (1984) and Peer (1990) associate cumulative growing degree days (GDD) directly to forest growth. GDDs can also be related to nutrient release rates (Solomon et al. 1984). Secondary responses include changes in disease mortality and growth rates in response to changes in nutrient availability.

GDDs are usually computed as a temperature deviation from some physiologically significant base temperature. Upper and lower temperature thresholds representing physiologically limiting conditions may also be defined. In these cases, GDD is assigned a value of zero. These relationships are defined for forests in the New England region of the United States as in Eq. 1.

$$
\text { GDD }=\left\{\begin{array}{cl}
0 & \text { if } T_{\min } \leq T_{1} \\
\left(T-T_{\mathrm{b}}\right) & \text { if } T_{\min }>T_{1} \\
& T_{\max }<T_{2} \text {, and } \\
& T \geq T_{\mathrm{b}} \\
& \text { if } T_{\max } \geq T_{2}
\end{array}\right.
$$

where $T=$ mean daily temperature, $T_{\max }=$ daily maximum temperature, $T_{\min }=$ daily minimum temperature, $T_{\mathrm{b}}=$ mean daily base temperature, $T_{1}=$ temperature 
below which no significant growth is assumed to take place, and $T_{2}=$ temperature above which no significant growth is assumed to take place.

Solomon et al. (1984) state that forest processes begin between 0 and $10^{\circ} \mathrm{C}$. According to Kozlowski (1985), growth of most trees is optimal between 20 and $35^{\circ} \mathrm{C}$, depending on the species. Therefore, $T_{1}$ is assumed to be $0^{\circ} \mathrm{C}$ and $T_{b}$ is assigned a value of $10^{\circ} \mathrm{C}$. No upper growth limit was set for the present application and so the third condition was dropped.

\section{Freezing temperatures}

The frequency and intensity of spring freezes can effect spring-germinating seeds and mature trees. Primary responses to late hard freezes are defoliation and, in extreme cases, death. A freeze analysis can be used to confirm or supplement observations of adverse weather conditions that might cause growth decline and tree mortality. Late spring frosts, along with drought, wind, moisture excess and high temperatures, are implicated in eastern hardwood dieback and decline (Millers et al. 1989). Although unusually low temperatures can damage and kill certain tree species, damage most commonly occurs from frosts in late spring.

Other factors related to frost/freeze damage are the duration of stressful temperatures and the degree of cold hardiness in affected plant tissues at the time of freeze (Kozlowski 1985). The cooperative data set provides only 24 -hour extremes with no indication of persistence within the day. In the present analysis, a hard freeze is recorded if the 24 -hour minimum temperature is $-2.2^{\circ} \mathrm{C}$ or colder.

\section{Warm (wet) snowfall}

Snow has a variety of implications for forest ecosystem health and productivity. An insulating blanket of snow protects tender understory species from winter desiccation or damage from periodic soil heaving. Snow also provides an important source of surface water storage. Wintertime evapotranspiration is low and substantial supplies of moisture can be held until spring. A slowly melting layer of snow in the spring releases moisture and nutrients in a fashion that permits maximum vertical infiltration and minimum surface erosion.

When ice crystals fall through a layer of relatively warm air, the crystal surface melts. These 'wet' flakes then stick to any surface they contact. The accumulated weight of this trapped liquid water on leaves and branches causes loss of limbs and uprooting of entire trees. For example, the 'warm snowstorm of May 9 ,
1977' (Gedzelman \& Lewis 1990) was one of the latestoccurring major snowstorms in the lower Hudson River Valley ever recorded. The accumulated weight of the wet snow on newly sprouted leaves caused extensive destruction to trees

\section{METHODOLOGY}

Once identification and acquisition of several forestrelevant climate variables was completed, the evaluation of our hypothesis of regional forest/climate interactions could begin. First, a list of 'quality' weather data observation locations was assembled. These stations had reported for a minimum of $30 \mathrm{yr}$ (records begin in 1961 or earlier), all station were active as of 1991 and station records were $90 \%$ or more complete. Next, a geographic information system (GIS) was used to associate each forest sampling area (hexagon) in Fig. 1 with a weather observing site from the quality controlled station list. Twenty-nine percent of sampling hexagons are within $15 \mathrm{~km}$ of a temperature observation site, while $38 \%$ of sampling sites have access to data within $30 \mathrm{~km}$ and $33 \%$ of sampling sites must be characterized by weather observations more than $30 \mathrm{~km}$ distant. The maximum separation is $110 \mathrm{~km}$. All distances greater than $42 \mathrm{~km}$ are for sampling hexagons located in northern Maine. Future studies should examine the availability of Canadian data of sufficient quantity and quality to fill some of these gaps

Contour maps of temperature and precipitation statistics were constructed to characterize aspects of the long-term, or background climate of the New England region against which change could be assessed. Contours of data from the selected 'nearest' stations were generated using a bi-harmonic cubic spline expression. Annual values were based on the months October through September rather than a calendar year. This period was chosen so that 1990 values represent events leading up to and including the forest sampling period and do not overlap previous or following growing seasons.

Area-weighted regional time series were also prepared as background summaries. Since the NEFHM sampling design generates a nearly uniform grid of points, weighted area means are constructed by associating climate values with their appropriate sampling hexagons, summing and dividing the results by the total number of hexagons in the region. Examples of the use of these products in a statistical summary are found in Brooks et al. (1992a, b).

While the previous 2 analysis types were considered a direct application or operational mode, a third analysis represented an exploratory study. There is 
an increasing number of scientists who deal with natural disturbance and report their research results in the ecological literature. However, climatologists have as yet to develop the analysis tools needed to facilitate direct interaction between climatological and ecological disciplines. To approach this linkage, a decadal summary was prepared consisting of drought, GDD sums, spring freeze dates and warm spring snowfall event dates in terms of the percent of total area impacted. PDSI values, small GDD totals, and spring freeze and snowfall dates are included if, based on the entire climate record for a station, the current value is expected to occur fewer than once in $20 \mathrm{yr}$. The purposes of this summary are: (1) to facilitate visual identification of short-term trends in forest related climate variables; (2) to identify the frequency and size of regional-scale climate events; and (3) to identify associations among the various climate conditions. This kind of summary does not quantify the amount of forest damage or forest response to these stresses. Such detailed information is crucial for species specific modeling studies, but regional assessments must cross species and specific ecosystem types. The impact of environmental stress will vary with ecological system (although all of these measures reflect local conditions) and combinations of stresses may result in threshold behavior (discontinuities) or non-linear increases in damage or response. A consistent intensity of stress across stressors is employed which permits meaningful generalizations of size/ frequency relationships. The regional quantification of such characteristics has been identified as a crucial requirement for the development of a formal theory of ecosystem response to disturbance.

\section{RESULTS AND DISCUSSION}

An example of a contour map generated for the operational EMAP program is given in Fig. 2. Two particular issues were explored when developing this analysis: representation of the geographic area through selection of weather stations and selection of contour interpolation technique. To address the first issue (station selec- tion), a GIS was used to associate 3 time-dependent sets of climate stations with the sampling hexagons. The cooperative network was stratified by variable and the availability at each station of $30 \mathrm{yr}, 10 \mathrm{yr}$ or 1990 (1 yr) of data. An examination of these station sets shows increasing densities of observing stations and general improvement in the quality (completeness and continuity) of station records.

Eighty cooperative network stations possessed $90 \%$ or more complete records for observations begun in 1961 or earlier and were selected as being 'nearest' to a potential FHM sampling plot. This number increased by $34 \%$ to 107 by 1990 . None of the original 80 stations was permanently replaced by the establishment of new cooperative stations, but some longer-record

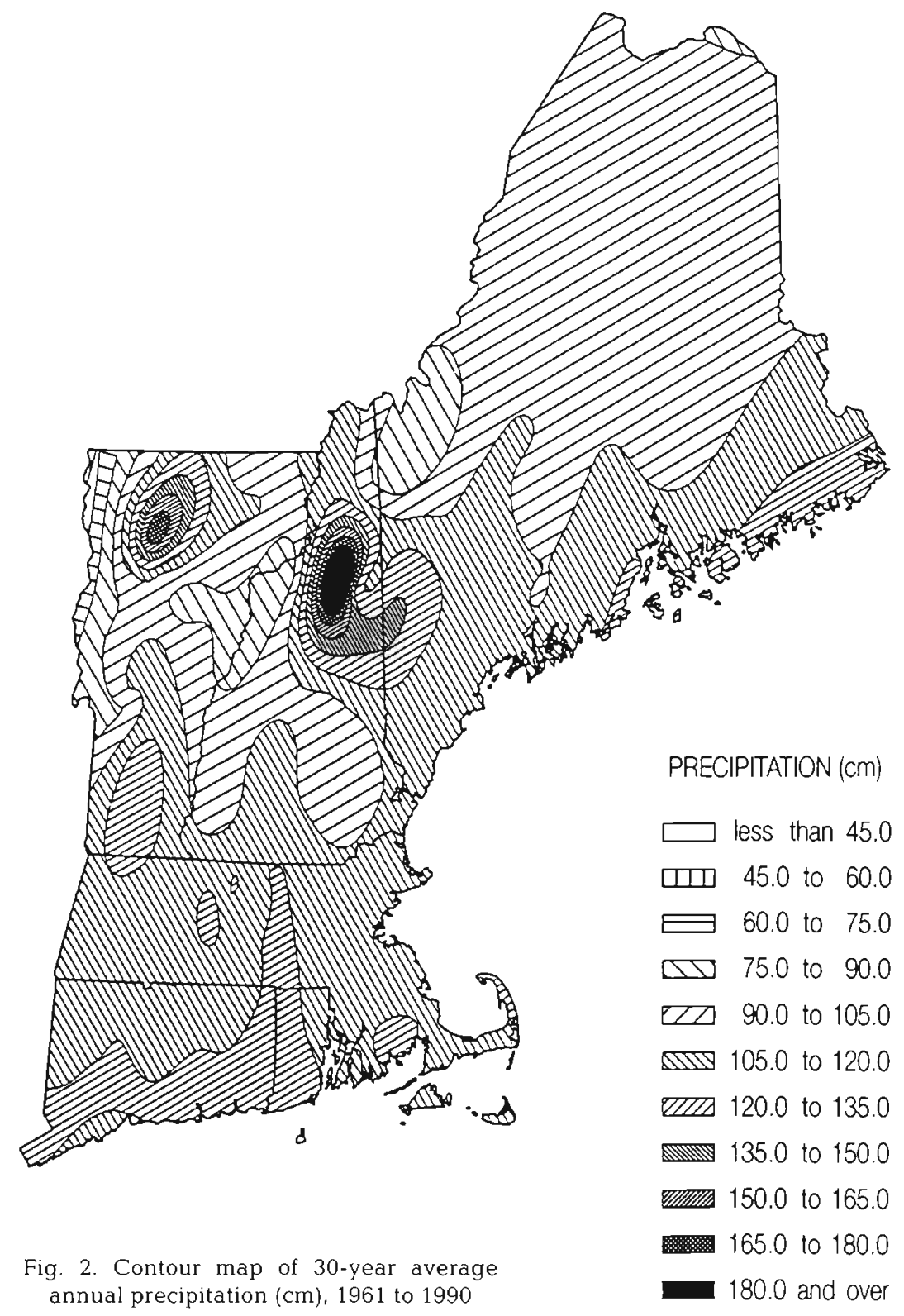


stations do move in and out of the data set depending on the time period considered. For temperature, these stations are all located in the state of Maine. None of these stations was abandoned, but they were removed from the database because record completion dropped below our $90 \%$ criterion. Fig. 3 alerts us that this movement of temperature stations into and out of the database could impact intermediate climate analyses because the majority of departing sites are higher elevation locations (open circles) that are not replaced by the introduction of new cooperative stations (solid stars). Fig. 4 provides an estimate of the increased uncertainty introduced into an analysis by such network changes. The figure illustrates areas of difference between contours of mean decadal (1981 to 1990) temperature using the 30 -year and 10-year station sets. The same contouring algorithm and contour model parameters were applied in each case. Positive values indicate areas in which higher (warmer) decadal temperatures were estimated from the 10 -year network than from the 30 -year network. Negative values indicate areas in which the 30-year network estimates of mean decadal temperature are warmer than those using the 10-year network. Although only the state of Maine is shown, all surrounding data were used to estimate the contours. Fig. 4 illustrates that uncertainty resulting from changing station density and location in Maine during the $1980^{\prime}$ s ranges from -1.5 to $+1.5^{\circ} \mathrm{C}$.

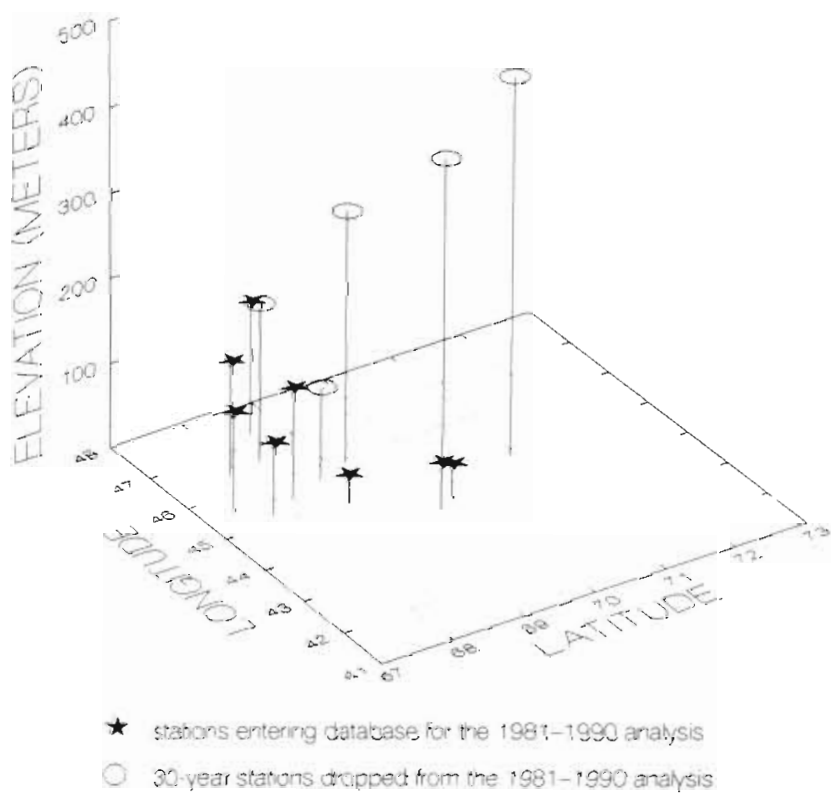

Fig. 3. Maine temperature station locations. Open circles represent stations absent from the database for the 1981 to 1990 averaging period. Solid stars represent stations added to the original 30-year station database for the 1981 to 1990 averaging period

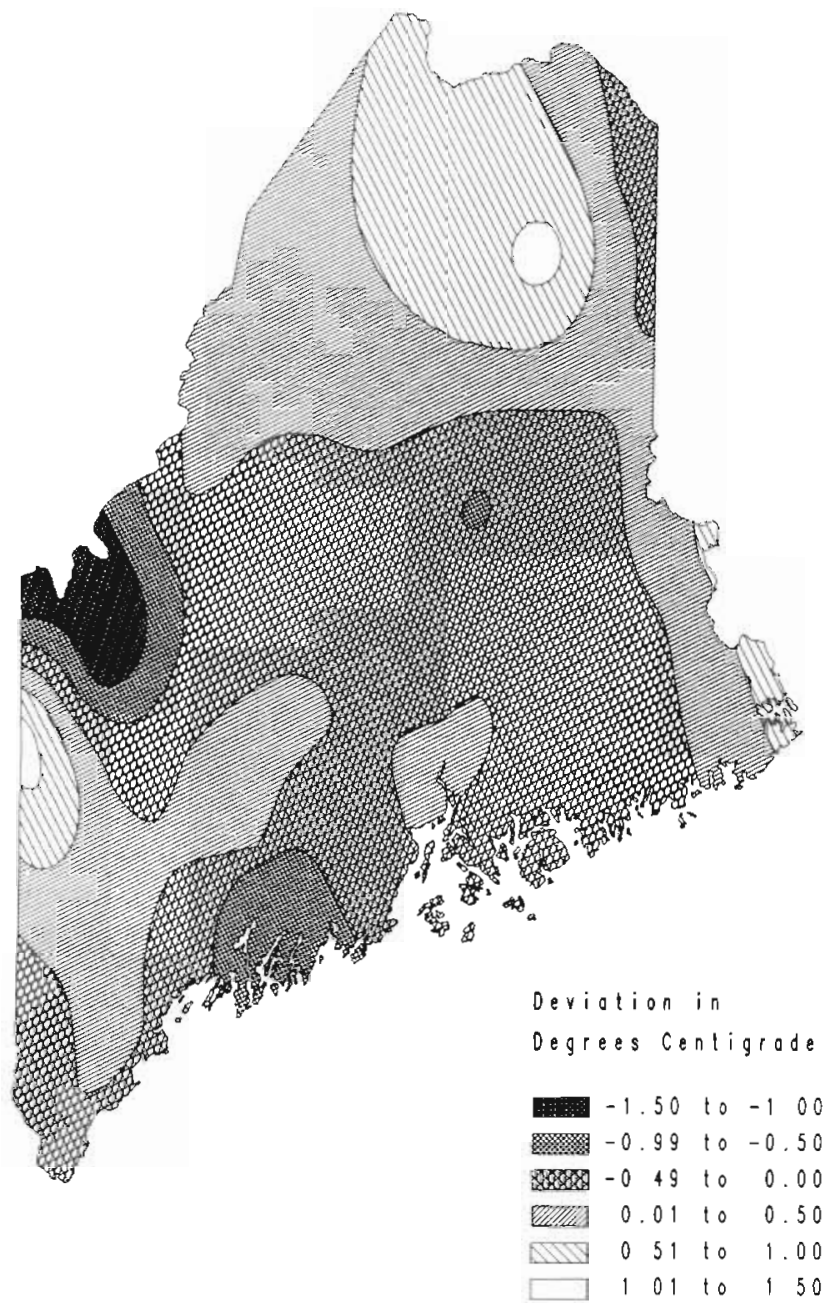

Fig. 4. Impact of climate network location changes on the estimation of mean annual temperature, 1981 to 1990 (10-year station set contour values minus 30 -year station set contour values\}

Although similar results were obtained for the precipitation station set (Fig. 5), the dropped stations are more geographically diverse and, although not colocated, several new higher elevation sites were added to the database. The net result, then, is some loss of representation during the 1980 's, but not to as great an extent as for temperature. To avoid introducing additional error into the climatological analysis from station network changes such as these, the 30 -year station set was adopted.

Next we considered the effects of the method of data interpolation. Although the bi-harmonic technique was used, methods such as kriging or cokriging could be applied to climate means (e.g. Dingman et al. 1988). In fact, other scientists working with more limited environmental data sets, e.g. ozone, were already using these techniques. Compatibility of methodology is 


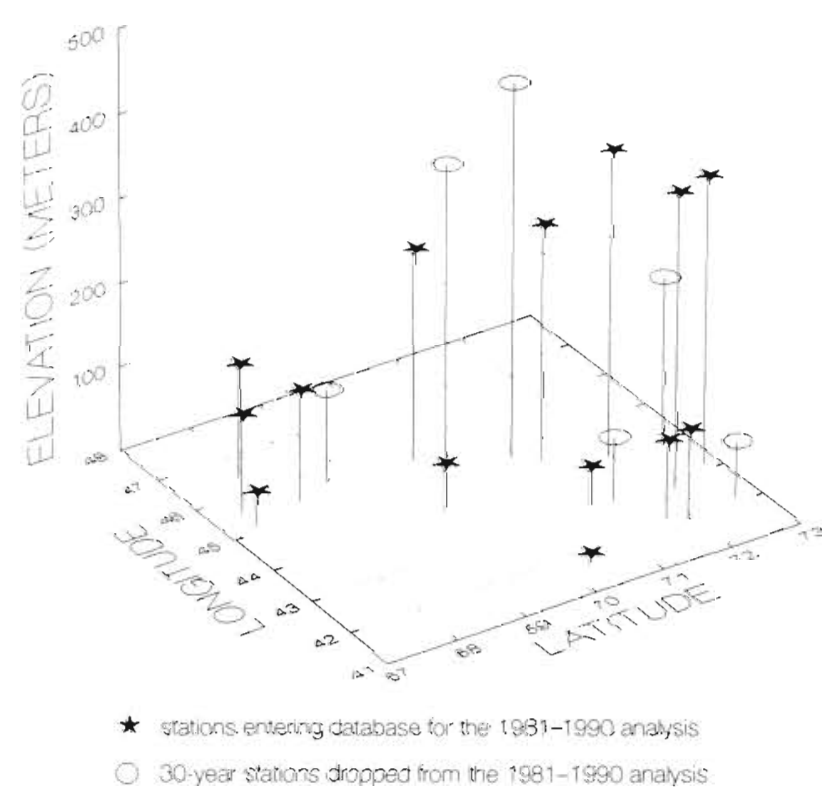

Fig. 5. New England precipitation stations locations. Open circles represent stations absent from the database for the 1981 to 1990 averaging period. Solid stars represent stations added to the original 30-year station database for the 1981 to 1990 averaging period

certainly an important consideration, but the use of cokriging, in particular, greatly complicates the analysis process so that, unless the data are extremely sparse, the use of this technique is not desirable in an operational setting.

An example of area-weighted time series is presented in Fig. 6. Although it appears to provide a fairly simple summary of climate conditions throughout the region, it was determined that inappropriate conclusions could be drawn. For instance, Fig. 6 suggests a trend in the date of last hard spring freeze for the New

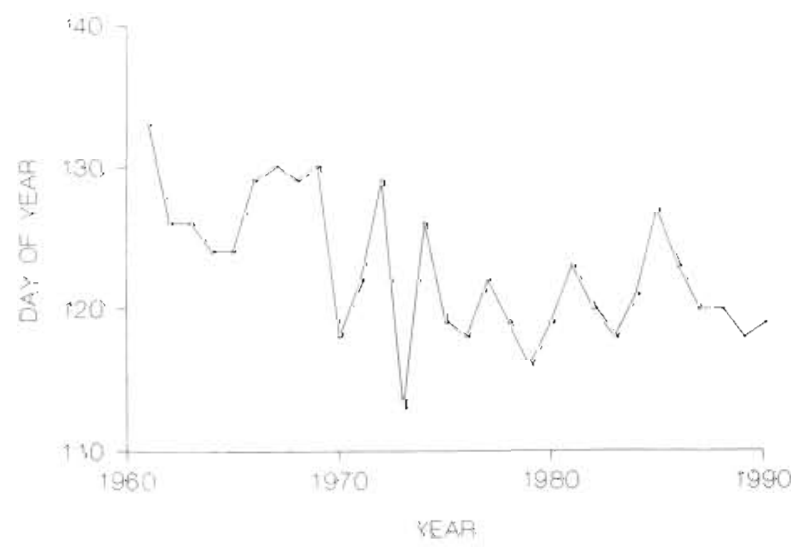

Fig. 6. Area-weighted time series of date of last spring hard freeze (minimum temperature $\leq-2.2^{\circ} \mathrm{C}$ )
England region. Significant bias may be introduced into a time series when a large number of forest sites must be represented by a single weather observation. In New England, all such cases occur in Maine - the state which also dominates the region in area. Thus, a situation exists in which the greatest influence on the weighted regional estimate is derived from the area with the least data. Although other means of aggregating the observations could be explored, the issue of spatial representation of climate variability in sparsely populated areas has yet to be satisfactorily addressed. In the future, remotely sensed data from Doppler radar and space-based earth observing systems should play a vital role in improving the climatological characterization of such geographically remote areas.

The accuracy of climatological data and summaries aside, a second fundamental question concerns the importance of such changes for forest ecosystems. For instance, if we assume that existing vegetation is ideally adapted to prevailing climatological means and extremes, how great a change is necessary before detectable ecosystem responses occur? Although the majority of plant growth and development can be generalized as responding to modal (most frequent or dominant) climate conditions, it is extreme conditions or events that most severely constrain species range and potential productivity. Responses to trends in, for instance, annual temperature range would most likely be observed at the margins of species range (ecotones). Recent research reported in Karl et al. (1991) suggests trends towards warmer winter minima over large portions of the northern hemisphere. Warmer minimum temperatures could create conditions in these areas favorable for expansion of marginal southern species into existing ecotones, or facilitate expansion of the ecotone itself. One goal of this study is to develop ways of describing climatological conditions so that associations between climate conditions (e.g. means, trends and variability) and indicators of forest status and health can be postulated and tested. If such associations can be confirmed, then research aimed toward the development of predictive response models can be pursued.

Under our hypothesis, it is assumed that existing vegetation has adapted to median climatological conditions and random, stressful conditions that occur relatively frequently. Excursions from these conditions represent situations that could result in ecosystem change. The more infrequent (rare) the event, the more likely that there will be an observable ecological response. In this sense, frequency is an indicator of the potential magnitude of disturbance response. Some scale analyses indicate that return periods of 1 event in 100 growing seasons would be the most appropriate frequency to consider (Gosselink et al. 
1990). Unfortunately, few weather station records permit the direct estimation of these extreme values. To illustrate the development of a regional summary product, a return period of 1 event in $20 \mathrm{yr}$ is calculated from the climate station record for selected variables.

Fig. 7 contains a decadal summary of drought, GDD, spring freeze and spring snowfall stress in terms of the total area impacted. Spring freeze and spring snowfall events are deemed to be disturbances if, at a given weather station location, such conditions occur on a later spring day than that reported once in $20 \mathrm{yr}$. A GDD event is declared to be a disturbance if a smaller growing season total (April through September GDD sum) has been reported less than one time in $20 \mathrm{yr}$. A drought disturbance is noted when the minimum annual monthly PDSI for a climate division, for an October through September year, is less than that expected once in $20 \mathrm{yr}$. In all cases, this results in a PDSI value in the range of 'moderate' to 'severe' meteorological drought (Palmer 1965). Fig. 7 indicates that one large-scale drought event occurred in the New England region during the last decade. Late spring freezes were associated with at least a few sampling locations during 9 of the 10 years. The freeze event of largest spatial extent occurred in 1988 and impacted $8 \%$ of the region. Late spring freezes and unfavorably cool growing conditions throughout the year (as indicated by small GDD totals) were not clearly associated. The most widespread GDD event was reported in 1982 and affected $16 \%$ of the New England region. The most extensive late spring snowfall event of the last decade occurred in 1990 and impacted $20 \%$ of New England. Thus, during the decade of the 1980s, at the level of stress represented by a 20-year return period, the largest-scale events (spatially) were late spring snowfall and low GDD totals. During this decade, late spring freezes were rather small-scale events that impacted roughly the same amount of area each year. Large-scale drought was not a critical factor during this period.

The distribution of disturbance intersections, in combination with an examination of their dispersal throughout the geographic region, can be used to further describe the disturbance regime during this period. Fig. 8 shows the distribution of the number of event 'intersections' with NEFHM sampling hexagons over the decade. A hexagon intersection is said to occur when a disturbance event is identified in the climatological record associated with a particular NEFHM sampling hexagon. The maximum possible number of intersections for each hexagon is 40 (drought, freeze, snow and
GDD for each of 10 years). The areas of interest are the 'tails' of the distribution. Hexagon counts located at the lower tail (zero intersections) represent areas experiencing few climate disturbances (as defined by our 4 events and 20 -year return period). If we assume that existing ecosystems are best adapted to modal climate conditions, then these could be construed as regions experiencing favorable conditions for growth and development of existing forests. If these conditions follow a relatively stressful period, positive changes in ecosystem status or health representing ecological recovery might be observed. Negative changes in ecosystem status reported in these areas would most likely derive from sources other than the climate stresses studied here.

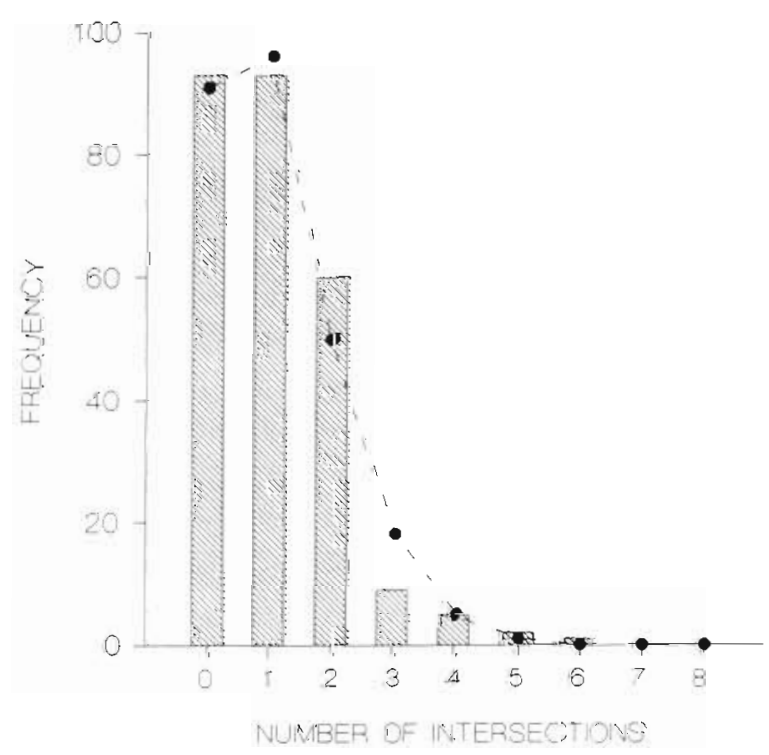

Fig. 8. Distribution of hexagon and climate event intersections, 1981 to 1990 (frequency in \%). Filled circles connected by dashed line are Poisson values for the distribution of sample intersections 
Hexagons in the upper tail of Fig. 8 represent areas subject to a larger number of unusual climate events. Evidence of ecosystem response to these factors could take the form of changes in ecosystem structure, characteristics or overall system health (resistance to pest and disease injury).

Guidelines presented in Hastings \& Peacock (1974) state that if a sample mean and variance are approximately equal, the data can be modeled by a Poisson distribution. The sample in Fig. 8 has a mean of 1.05 and a variance of 1.108. Poisson values for the distribution of sample intersections were estimated using Eq. 2 and are shown in Fig. 8 with filled circles and a dashed line.

$$
f(x)=s^{x} \frac{e^{-s}}{x !}
$$

where $s=$ sample mean $=1.05$ events per decade; $e=$ constant $=2.732 ; x=$ intersection category $(0$ to 8$)$.

If event intersections during the period 1981 through 1990 were independent and random, 6 forest hexagons would be expected to report 4 or more event intersections during the decade. Our sample contained 8 such locations. Although this is slightly in excess of the random, expected value, subsequent $\chi^{2}$ and Poisson adequacy tests do not suggest the data deviates in a statistically significant way from the independent, random Poisson model.

Fig. 9 contains the location of hexagons reporting 4 or more event intersections. Five cooperative weather network stations define 3 clusters of hexagons reporting 4 or more disturbance intersections. Three of these 5 stations define the area contained within Massachusetts, indicating this is likely to be a climatologically active region. To better understand the nature of the remaining 2 intersection areas, hexagons reporting 3 intersections were added to the map. These locations are indicated on Fig. 9 by the symbol $X$. The result is that the New Hampshire area remains vague and could reflect 'noisy' weather data or local-scale phenomena rather than a pattern of regionally important climatological disturbances.

The results of the 1981 to 1990 analysis suggest that this was a climatologically quiet period. By way of comparison, a similar regional hexagon analysis was performed for the decade of the 1960 's. This is a period of particular interest because high elevation red spruce decline is suggested to have been triggered by a combination of climate and pollution stresses during this time (Johnson et al. 1988).

Johnson et al. (1988) attribute red spruce declines in the White, Green and Adirondack Mountains to a series of cold winters in 1961, 1962 and 1963. Although there is agreement that this is a likely source of decline at higher elevations, there is some disagreement concerning the interpretation of tree-ring pat-

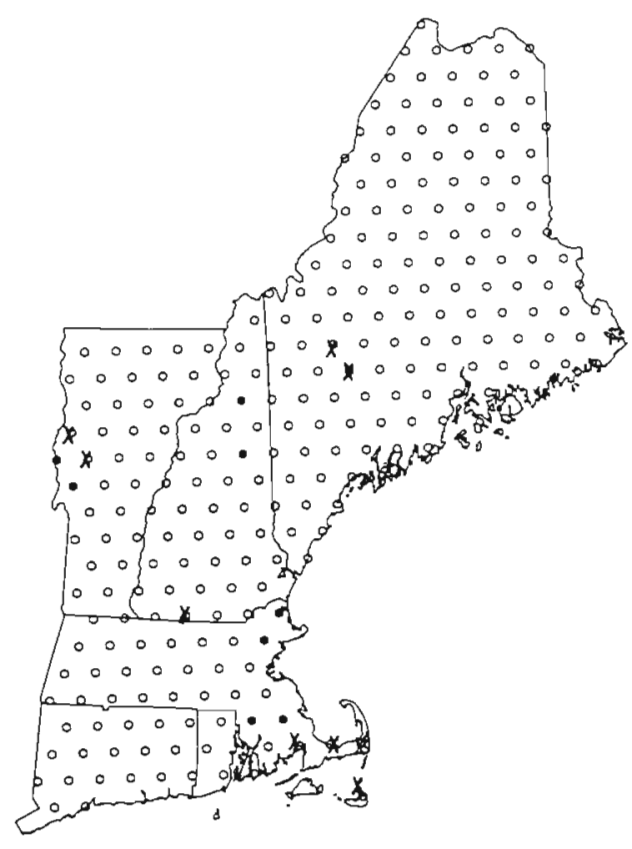

Fig. 9. Location of sampling hexagons reporting 4 or more climate event intersections (solid hexagons) and 3 or more intersections (marked by X), 1981 to 1990

terns and mortality elsewhere (Van Deusen et al. 1991). Johnson et al. (1988) found conflicting evidence of the association of PDSI with ring width, but drought as an additional source of stress cannot be entirely discounted.

Johnson et al. (1988) found close relationships of cold early winters prior to the growing season and warm late summers of the previous years to red spruce ring chronologies. Such unusually late warm conditions could easily be associated with the multiple-year drought of 1964 to 1966 . As yet there is no physiological explanation for these relationships other than that perhaps the new shoot material does not hardenoff properly when late summer is too warm.

Fig. 10 is the same type of presentation as Fig. 7, but contains data for the period 1961 to 1970 . It is immediately apparent that this is a more active climatological period. Three consecutive large-scale drought years dominate the figure from 1964 into 1966. Late snowfall events also are more frequent and impact a larger area than during the 1980's. Nearly one-third of New England was impacted by a late spring freeze in 1961 and $20 \%$ was impacted in 1969. Small GDD totals do not appear to be of major importance in the 1960's.

Fig. 11 contains the distribution of hexagon/climate stress intersections. A sample mean of 3.28 and variance of 1.92 are computed from these data. Applying the Hastings \& Peacock (1974) guidelines for mean greater than variance, a binomial distribution is recommended. Binominal values for the distribution of sample inter- 


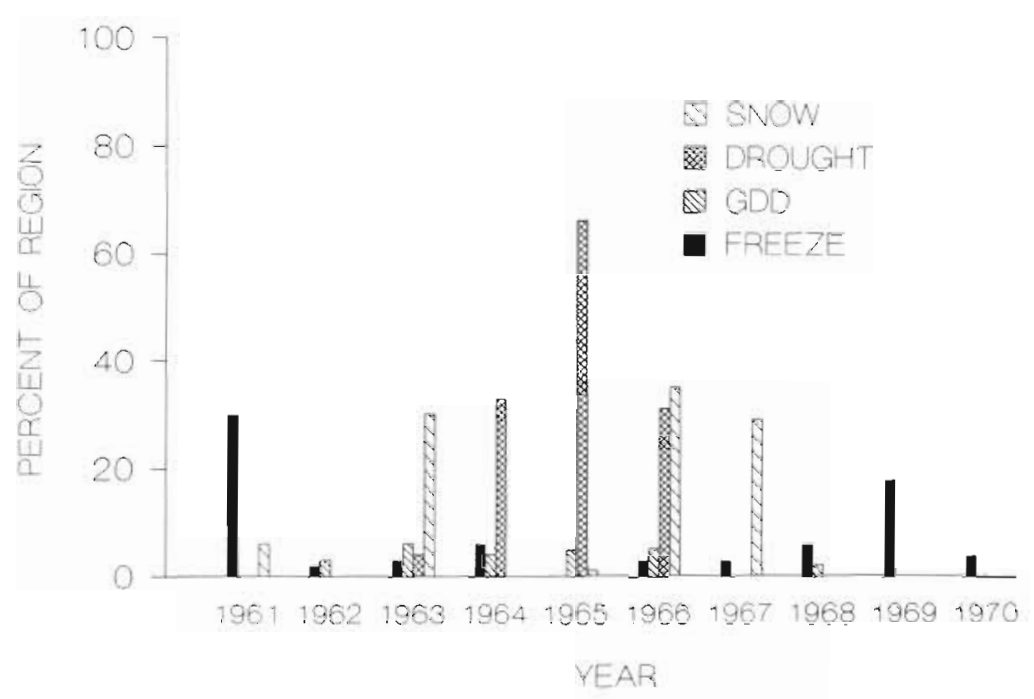

Fig. 10. Percent of New England region impacted by climate stress, 1961 to 1970

summary product comprised of climate events of differing temporal and spatial scale. The degree to which this confines meaningful regional disturbance associations with regional forest response indicators will be addressed in future research.

\section{SUMMARY AND CONCLUSION}

A working hypothesis has been developed concerning the relationship between climate and ecosystem status, trends and health based on concepts of ecological persistence, recurrence and climate related disturbance. Research reported in the present summary indicates that traditional statistical summaries

sections were estimated using Eq. 3 and are shown on Fig. 11 with filled circles and a dashed line.

$$
N f(x)=N \frac{m !}{x !(m-x) !} p^{x}(1-p)^{m-x}
$$

where $m=$ potential number of intersections per hexagon $=40$ per decade, $N=$ number of forest hexagons in the study region $=263, p=$ probability of an intersection with one hexagon $=\sum x / N m=0.08, x=$ number of intersections observed ( 0 to 8 ).

Fig. 11 indicates that if event intersections were independent and random, 105 hexagons would report 4 or more intersections. 113 such hexagons were actually noted. A $\chi^{2}$ test tells us that the pattern of intersections is not random. This is confirmed visually by Fig. 12. Consideration of the events contributing to Fig. 10 suggests that prolonged and wide-spread drought during the 1960's is the primary source of differences between Figs. 8 and 11.

A comparison of the 1961 to 1970 and 1981 to 1990 analyses illustrates 3 important points. First, disturbance event characteristics can vary dramatically from decade to decade in terms of size, frequency and geographic distribution. Using constant probability criteria, decadal means ranged from 1 to 3 events per hexagon. Spatial patterns ranged from rare and nearly random to relatively common and spatially correlated.

Second, future research should address the inclusion of disturbance persistence in the regional analysis. Although all events were defined with equal probability of magnitude ( 1 event in $20 \mathrm{yr}$ ), there is a persistence element, particularly in drought, that should be assigned a probability as well.

Thirdly, the 1960's analysis illustrates the difficulty of constructing and interpreting a regional climate such as contour maps and weighted time-series must be constructed and interpreted with care for largescale ecological assessments. Climatologists can make significant contributions to the quality and scientific credibility of such assessments by helping their fellow researchers avoid database (contour map discussion) and issue-oriented (spurious time-series trends) pitfalls.

Pickett \& White (1985) conclude that in order to develop a theory of ecosystem response to disturbance composed of unambiguous, testable hypotheses and capable of making sound mechanistic predictions, the relevant variables of disturbance must be established.

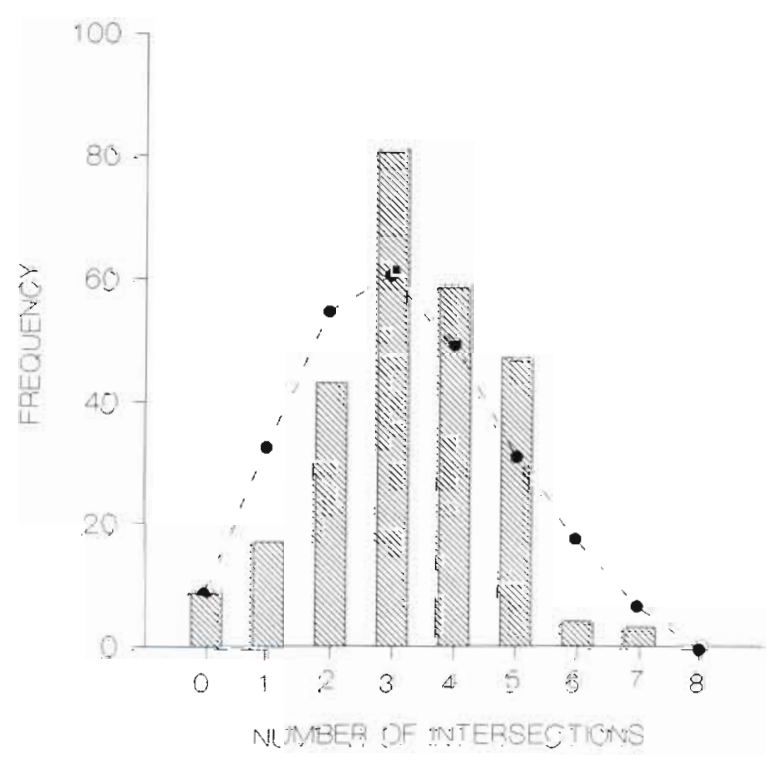

Fig. 11 Distribution of hexagon and climate event intersections, 1961 to 1970 (frequency in \%). Filled circles connected by dashed line are binomial values for the distribution of sample intersections 


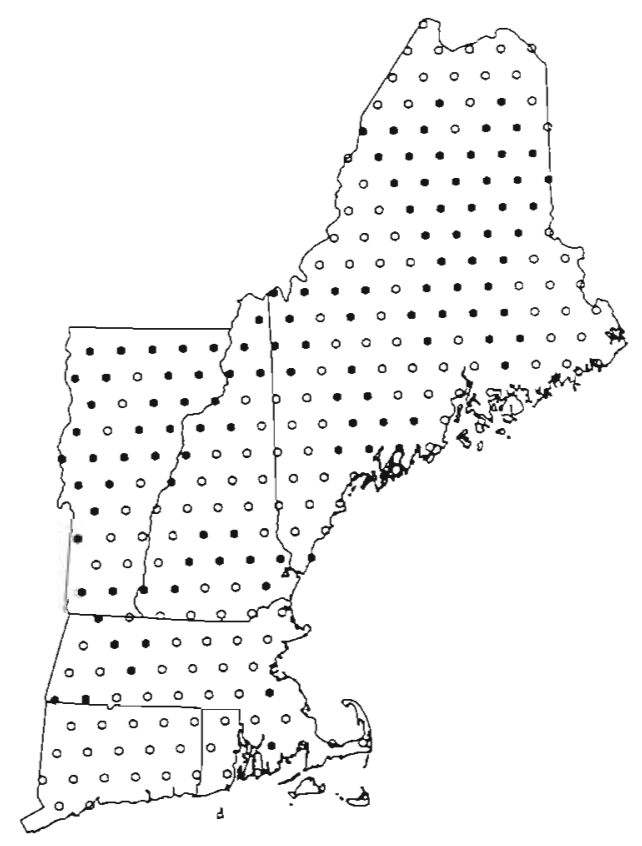

Fig. 12. Location of sampling hexagons reporting 4 or more climate event intersections (solid hexagons), 1981 to 1990

These include at least magnitude, frequency, size and dispersion. Existing climatological products that are designed to appeal to a general audience provide valuable background information. If, however, we are to correctly interpret and model forest/climate interactions as proposed by Pickett \& White, we must be certain to focus on the most pertinent aspects of the environment. Climate research regarding ways of summarizing and communicating this information in forms compatible with ongoing ecological research is lacking. As long ago as 1987 P. J. Michaels and B. P. Hayden identified climate disturbance issues and ready sources of climate data for such analyses, but few opportunities to develop these resources have been offered. Historically extreme values, for instance, against which current conditions and recent trends can be compared have yet to be estimated for some forestrelevant climate variables.

Pickett \& White conclude that the development of disturbance theory requires an explicit statement of the parameters of systems that can respond to disturbance. To be useful, climatological information must be provided in terms of the variables of disturbance pertinent to these response parameters. The research summarized here represents a first step in this process, i.e. the presentation of the location, magnitude, frequency, size and dispersion of climatological disturbance phenomena. The next step is to explicitly link observations of forest status and behavior with the unified climatological disturbance database to identify and more precisely define forest response parameters.
This has been done here in a cursory fashion, but a long process of research, integration and application remains before the role of climate/forest interactions in the overall earth system can be fully understood and predicted.

Acknowledgements. The authors thank Keith Eggleston of the New England Regional Climate Center for providing the 1990 New England climatological data. Thanks also go to Don Block and Karl Hermann for additional GIS assistance and George Mapp for database programming. Detailed reviews and helpful comments made by Peter Finkelstein and Brian Eder were also appreciated. The information in this document has been funded in part by the United States Environmental Protection Agency under contract number 68-02-4444. It has been subjected to Agency review and approved for publication. Mention of trade names or commercial products does not constitute endorsement or recommendation for use.

\section{LITERATURE CITED}

Alley, W. M (1984). The palmer drought severity index: limitations and assumptions. J. Clim. appl. Meteorol. 23: $1100-1109$

Bailey, J A. (1986). Weather and climate. In: Cooperrider, A. Y., Boyd, R. J., Stuart, H. R. (eds.) Inventory and monitoring of wildlife habitat. U.S. Dept of the Interior, Bureau of Land Management Service Center, Denver, p. 711-724

Biggs, R. B., Taft, J. L., Cronin, L. E., Tyler, M. A., Boynton, W. A. (1984). Chesapeake Bay anoxia: origin, development and significance. Science 223: 22-27

Botkin, D. B. (1980). A grandfather clock down the staircase: stability and disturbance in natural ecosystems. In: Waring, R. H. (ed.) Forests, fresh perspectives from ecosystem analysis. Oregon State Univ. Press, Corvallis, p. $1-10$

Brooks, R. T., Dickson, D., Burkman, W., Millers, I., MillerWeeks, M., Cooter, E., Smith, L. (1992a). Forest health monitoring in New England: 1990 annual report. Resource Bulletin NE-125. U.S. Dept of Agriculture, Forest Service, Northeastern Forest Experiment Station, Radnor, PA

Brooks, R. T., Frieswyk, T. S., Griffith, D. M., Cooter, E., Smith, L. (1992b). New England's forests: a baseline for the New England Forest Health Monitoring Program. Resource Bulletin NE-123. U.S. Dept of Agriculture, Forest Service, Northeastern Forest Experiment Station, Radnor, PA

Cooter, E. J. (1982). An Oklahoma soil moisture climatology. Operational weather modification, Vol. 6. Oklahoma Climatological Survey, Norman, OK

Cooter, E. J., LeDuc, S. K., Truppi, L., Block, D. R. (1991). The role of climate in forest monitoring and assessment: a New England example. EPA 600/3-91/074, U.S. Environmental Protection Agency, Atmospheric Exposure and Assessment Laboratory, Research Triangle Park, NC

Dingman, S. L., Seely-Reynolds, D. M., Reynolds, R. C. III (1988). Application of Kriging to estimating mean annual precipitation in a region of orographic influence. Wat. Resour. Bull. 24: 329-339

Eder, B. K., Davis, J. M., Monahan, J. F. (1987). Spatial and temporal analysis of the palmer drought severity index over the southeastern United States. J. Climatol. 7: 31-56 
Forman, R. T. T., Godron, M. (1986). Landscape ecology. John Wiley and Sons, New York

Gedzelman, S. D., Lewis, E. (1990). Warm snowstorms, a forecaster's dilemma. Weatherwise 43: 265-270

Gosselink, J. G., Lee, L. C., Muir, T. A. (1990). The regulation and management of bottomland hardwood forest wetlands: implications of the EPA-sponsored workshops. In: Gosselink, J. G., Lee, L. C., Muir, I A. (eds.) Ecological processes and cumulative impacts: illustrated by bottomland hardwood wetland ecosystems. Chap. 19. Lewis Publishers, Chelsea, MI

Hastings, N. A. J., Peacock, J B. (1974). Statistical distributions. Butterworth \& Co., London

Johnson, A. H., Cook, E. R., Siccama, T G. (1988). Climate and red spruce growth and decline in the northern Appalachians. Proc. natl Acad. Sci. U.S.A. 85: 5369-5373

Karl, T R. (1983). Some spatial characteristics of drought duration in the United States. J. Clim. appl. Meteorol. 22: $1356-1366$

Karl, T. R., Kukla, G., Razuvayev, V. N., Changery, M. J., Quayle, R. G., Heim, R. R. Jr, Easterling, D. R., Fu, C. B. (1991). Global warming: evidence for asymmetric diurnal temperature change. Geophys. Res. Lett. 18: $2253-2256$

Kozlowski, T T. (1985). Tree growth in response to environmental stresses. J. Arboricult. 11: 97-111

Michaels, P. J., Hayden, B. P. (1987). Modeling the climate dynamics of tree death. Bioscience 37(8): $603-610$

Miller, G. D. (1991). Forest health: where does it hurt? Am. For. 97: $46-48$

Millers, I., Shriner, D. S., Rizzo, D. (1989). History of hardwood decline in the eastern United States. Northeastern Forest Experiment Station General Technical Report NE-126, Broomall, PA, p. 39-40

Norton, D. J., Slonecker, E. T. (1990). The ecological geography of EMAP. Geolnfo Systems 1: $32-45$

Palmer, W. C. (1965). Meteorological drought. Weather Bureau Research Paper No. 45, Washington, DC

Peer, R. L. (1990). An overview of climate information needs

Editor: V. Meentemeyer for ecological effects models. Contract No. 68-02-4288, USEPA/ORD/AREAL, Research Triangle Park, NC

Pickett, S. T A., White, P. S. (eds.) (1985). The ecology of natural disturbance and patch dynamics. Academic Press, Orlando

Puckett, L. J. (1981). Dendroclimatic estimates of a drought index for northern Virginia. U.S. Geological Survey Water-Supply Paper 2080, Washington, DC

Runkle, J. R. (1985). Disturbance regimes in temperate forests. In: Pickett, S. T. A., White, P. S. (eds.) The ecology of natural disturbance and patch dynamics. Academic Press, Orlando, p. 17-33

Sadowski, A. (1975). Bulletin concerning technical procedures. Bulletin No. 130: Crop moisture index. NOAA/NWS bulletin to recipients of technical procedures bulletin series (mimeographed). NOAA, Washington, DC

Solomon, A. M., Tharp, M. L., West, D. C., Taylor, G. E., Webb, J. W. Trimble, J. L. (1984). Response of unmanaged forests to $\mathrm{CO}_{2}$-induced climate change: available information, initial tests and data requirements. Prepared for DOE under Contract No. W-7405-ENG-26, DOE/NBB-0053. Oak Ridge National Laboratory, Oak Ridge, TN

U.S. EPA (Environmental Protection Agency) (1990). Reducing risk: setting priorities and strategies for environmental protection. Publication SAB-EC-90-021, U.S. Environmental Protection Agency, Washington, DC

Van Deusen, P. C., Reams, G. A., Cook, E. R. (1991). Possible red spruce decline: contributions of tree-ring analysis. J. For. 89: 20-24

White, P. S., Pickett, S. T. A. (1985). Natural disturbance and patch dynamics: an introduction. In: Pickett, S. T A., White, P. S. (eds.) The ecology of natural disturbance and patch dynamics. Chap. 1. Academic Press, Orlando, p. 3-9

Woodward, F. I. (1987). Climate and plant distribution. Cambridge Univ. Press, Cambridge

Zahner, R., Saucier, J. R., Myers, R. K. (1989). Tree-ring model interprets growth decline in natural stands of loblolly pine in the southeastern United States. Can. J. For. Res. 19: $612-621$

Manuscript first received: February 6, 1992

Revised version accepted: September 8, 1992 